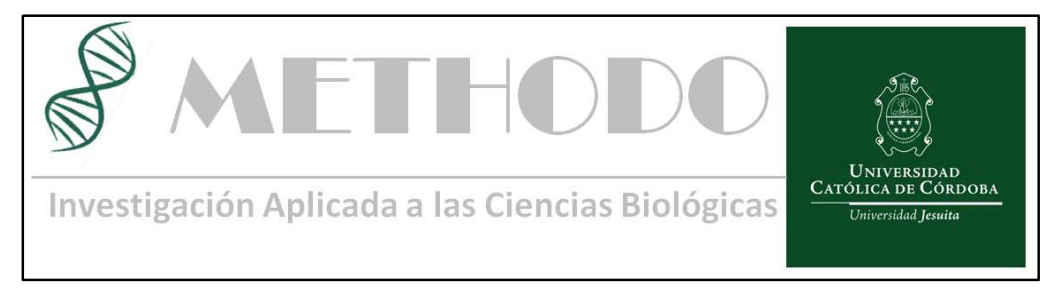

EDITORIAL Methodo 2019;4(1):01-02

DOI: $10.22529 /$ me.2019.4(1)01

\title{
La Investigación en la Universidad Católica de Córdoba. Un compromiso presente con futuro promisorio
}

\section{Research at Universidad Católica de Córdoba. A present commitment with a promising future}

Entre los objetivos fundacionales de la Universidad Católica de Córdoba, la investigación es uno de los medios indispensables para la consecución de su finalidad, a saber, "la búsqueda de la verdad y la promoción total del hombre mediante la formación humanística, social, científica y profesional de los estudiantes"1. No obstante, como actividad sistémicamente organizada, y tal como ha sucedido en otras universidades de gestión privada en Argentina, la investigación es en cierto modo reciente. ${ }^{2}$ Hoy, como fruto de un ininterrumpido proceso de maduración colegiada, es una opción de agenda cotidiana.

En efecto, ya la política y estrategia de la investigación en la Universidad Católica de Córdoba, plasmada en 2007, ${ }^{3}$ y el actual Plan de Desarrollo Institucional, plantean la misión de la Universidad en vistas a incidir "en la construcción de un orden social más justo, mediante la formación de graduados y graduadas competentes y comprometidos con su realidad (docencia); a través de la producción de conocimiento socialmente pertinente (investigación); y mediante la proyección social del mismo (extensión), a fin de incidir en políticas públicas que mejoren la calidad de vida, en particular de los sectores más desfavorecidos de nuestra sociedad". ${ }^{4}$

En este marco, la Universidad Católica de Córdoba decidió impulsar y apoyar "de manera preferencial las investigaciones de carácter interdisciplinario", y se procedió entonces a una clara opción por líneas preferenciales de acción, que deberían "funcionar como principio orientador de las decisiones en materia de programas y proyectos en los distintos ámbitos de la Universidad". 5 La generación y desarrollo de excelencia en el conocimiento, de una progresiva calificación del cuerpo docente y de una significativa proyección social se postulan como objetivos distintivos de la investigación. Sinergia institucional, por oposición a la dispersión de esfuerzos, y el uso racional de recursos escasos, son rasgos que contribuyen a la obtención de resultados, en términos de verdad y justicia, atendiendo tanto a la investigación básica como aplicada, así como a la producción primaria, industrial y de servicios.

Revista Methodo: Investigación Aplicada a las Ciencias Biológicas. Facultad de Medicina. Universidad Católica de Córdoba. Jacinto Ríos 571 B Gral. Paz. X5004FXS. Córdoba. Argentina. Tel.: (54) 3514517299

/ Correo: methodo@ucc.edu.ar / Web: methodo.ucc.edu.ar | EDITORIAL Methodo 2019;4 (1):01-02 
Las áreas problema estratégicas del sistema de investigación son opciones de mediano plazo, en las que la Universidad Católica de Córdoba enmarca los proyectos y programas de investigación acreditables, y en virtud de las cuales destina recursos y energías. ${ }^{6}$ En el marco amplio de "orientaciones de valor u opciones" identitarias, a saber, los derechos humanos, la justicia, la ética y los pobres, aquellas “áreas-problema" definidas son: "Marginalidad, Discriminación y Derechos Humanos", "Medio Ambiente y Desarrollo sustentable", "Tecnologías aplicables”, "Salud de las poblaciones" y "Prácticas Institucionales y Políticas públicas".7 Cada una de ellas está atravesada por "ejes", o sea, "aquellos enfoques que son considerados, por su especificidad, como omnipresentes cualquiera fuese el Áreaproblema (...)". Los ejes acordados son "educación"; "persona e identidad social”; "políticas para el desarrollo" y "gestión estratégica de recursos". ${ }^{8}$

En definitiva, todas estas concreciones y proyecciones del presente permiten augurar un futuro inmediato muy promisorio. Acaso en este marco deba insertarse la reflexión en torno a la investigación traslacional.

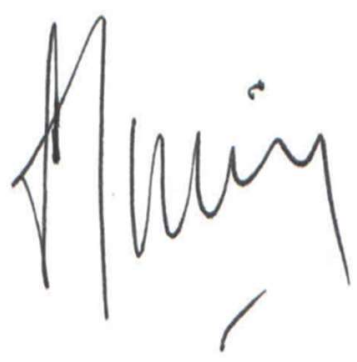

Dr. Alejandro Mingo

Secretario de Investigación y Vinculación Tecnológica.

${ }^{1}$ Estatuto Académico, art. $4^{\circ}$.

${ }^{2} \mathrm{Cf}$., por ejemplo, el panorama exhaustivo que ofrece O. Barsky y Otros, El estado de la investigación en las universidades e institutos de gestión privada en Argentina, Buenos Aires 2014; en línea: http://ppct.caicyt.gov.ar/index.php/debate-universitario/article/view/6500 (consulta: 11.03.19).

${ }^{3}$ Cf. Política y Estrategia de Investigación de la Universidad Católica de Córdoba (RR 492/2007).

${ }^{4}$ Plan de Desarrollo Institucional Universidad Católica de Córdoba 2015-2020, "II. Misión de la Universidad Católica de Córdoba" (cursiva nuestra).

${ }^{5}$ Cf. Política y Estrategia de Investigación, Anexo, Introducción.

${ }^{6}$ Desde el año 2013, a través de convocatorias para toda la universidad, trabajan más de 100 equipos estables de investigación, que nuclean a más de 350 docentes. Todos los proyectos son evaluados según criterios de admisibilidad, pertinencia y calidad, por pares de la propia UCC, y por pares externos, categorizados 1 o 2 en el sistema de incentivos o con méritos equivalentes, y especialistas en las disciplinas específicas.

${ }^{7}$ Cf. Política y Estrategia de Investigación, Anexo, III.3.

${ }^{8}$ Cabe añadir, por una parte, que la alianza con CONICET, concretada desde 2012, ha sido muy importante para consolidar la investigación en la UCC. La creación de dos Unidades Ejecutoras de Doble Dependencia y otras tantas Unidades Asociadas son síntomas elocuentes de un sostenido crecimiento institucional. Actualmente la UCC cuenta con 20 investigadores de carrera, 34 becarios CONICET, 13 de los cuales son becas cofinanciadas por la UCC. Por otra parte, el servicio a empresas - I+D por encargo, servicios de capacitación y de laboratorio, asistencia técnica, financiación para empresas - y el apoyo a investigadores y profesores - ayudas y subvenciones, protección de resultados, impulso al emprendedor y a redes de cooperación, por caso - aparecen entre los principales objetivos de la Prosecretaria de Vinculación Tecnológica. 